\title{
The Impact of January Events on Stock Performance
}

\section{in the Egyptian Stock Market}

\author{
Mai Ahmed Abdelzaher ${ }^{1}$ \\ ${ }^{1}$ Faculty of Commerce, Cairo University, Cairo, Egypt \\ Correspondence: Mai Ahmed Abdelzaher, Faculty of Commerce, Cairo University, Cairo, Egypt.
}

Received: January 9, 2019

Accepted: January 28, 2019

Online Published: February 7, 2019

doi:10.5430/afr.v8n1p174

URL: https://doi.org/10.5430/afr.v8n1p174

\begin{abstract}
This paper aims to evaluate the effect of the January 25 revolution on stock performance in the Egyptian market during 2010-2012 by analyzing its effects on trading volume, market return fluctuation, and closing price. These variables are analyzed pre- and post-January 25 revolution using the Descriptive statistics group unit root test, cointegrating equation model, GARCH model, and ARCH model. The results indicate that there is a significant positive relation between the January events and return fluctuation and no significant effect between the January events and trading volume; however, the trading volume decreased before, during, and after these events, and there is a significant negative relation between the January events and closing price.
\end{abstract}

Keywords: return fluctuation, trading volume, January events, Egypt

\section{Introduction}

The January 25, 2011, events in Egypt, which is one of the Arab Spring countries, started with a series of popular movements on a Tuesday to expostulate the economic, social, and political circumstance. These events had a negative impact on the Egyptian stock exchange market because they led to its stop trading for a long period of time. The market closed its doors on January 27, 2011, after wasting $16 \%$ of its market value in two sessions on January 26 and 27, 2011. Trade was unsettled until March 23, 2011 (Omran, 2015).

On the other hand, the Egyptian stock market testified a descend during trading in March 2011, when the EGX30 index fell over the course of month, trading was stopped at 5,464 points, a decline of $3.24 \%$, and for medium stocks, trading resorted to increase, with the EGX70 index increasing by $7.04 \%$, closing at 575 points, and the EGX100 index showing growth by $4.47 \%$ to close at 924 points. The gross value of stock traded during this month accomplished about 13.8 U.S. dollars, whereas the trading activity was about 972 million papers achieved over 209,000 transactions. The Nile Stock Exchange registered transactions valued at 25.1 million pounds, and a volume of 0.7 million papers achieved over 154 transactions during the month. The stocks earned $52.35 \%$ of the gross value of trade inside the chamber, whereas bond turnover accounted for about $47.65 \%$ during the month (Abdelbaki, 2013a).

Political events such as this revolution can also have a volcanic impact on stock market volatility because of their economic and social implications. On the one hand, inversion motions expand an chance for Middle Eastern and North African countries to improve a more apparent and effective governance to release their economic prospective. On the other hand, political instability caused by the unset could clear itself in stock market rotation and fluctuation reactions, shaking international investor trust in the territory Chu et al., 2014).

\section{Literature Review}

This part provides an overview of the academic literature on political events. Through a review of the literature, the researcher can identify the research gap and thus formulate the hypotheses of the study. The literature was arranged to examine the most common points that affect political events as follows: events and return fluctuation, and events and trading volume.

\subsection{Events and Return Fluctuation}

Beaulieu et al. (2005) examined the effect of political risk on the fluctuation of stock returns in the Canadian stock market from 1990 to 1996 using the GARCH model. They concluded that political news plays a serious role in the 
volatility of stock returns and that investors do not need a risk premium, meaning that political risk is diversifiable (Beaulieu et al. 2005).

Khan et al. (2013) examined the effect of political events on share prices. They used data extracted from the financial sector of Pakistan for the period from 2007 to 2010, using the event study methodology. The data were analyzed through period sample T-test statistics. They concluded that political events have a significant impact on stock prices, and prices behave negatively when a major event emerges on the international front (Khan et al., 2013).

Abdelbaki (2013b) showed that the January 25 revaluation greatly influenced development and growth in the Egyptian economy. He found that where the growth rate decreased in 2011, it also led to negative growth during the first quarter of 2011 and that the sectors that support the economy in the provision of hard currency fell sharply in revenue (Abdelbaki, 2013a).

Omran (2015) examined the relationship between the January 25 revaluation and price changes and applied it to the Egyptian stock exchange market during the period from 2009 to 2013. The variables of the study were total market value, exchange rate, and inflation. Omran (2015) concluded that the January events had a negative impact on the Egyptian stock market, with the market closing its doors on January 26 and 27, 2011, and trade pendent until March.

Murtaza et al. (2015) studied the impact of political events on stock market return. The variables of the study were abnormal and actual returns. They used the event study methodology, extracting data from the Karachi stock exchange market in the period from 2007 to 2012. They concluded that political events that cause changes in government policy have a significant impact on stock market return (Murtaza et al., 2015).

Mnif and Kammoun (2015) used two methods - the window method and the C-max method-to study the effect of political uncertainty during and after the revaluation on the stock market. They found that the Arab Spring greatly affected stock market performance. However, there were enormous declines in equity prices that persisted from the beginning of the revolution (Mnif \& Kammoun, 2015). The Egyptian stock exchange was closed for 2 months.

Adhikari and Phuyal (2016) studied the relationship between political events and stock market volatility in Nepal in the period from 2003 to 2013. They examined the relationship between the NEPS index and inflation, gold price, brokerage firms, and volume of securities traded. They used a simple linear multivariate regression analysis, concluding that there was a linear relationship between the NEPS index and inflation, remittance, gold price, and volume of securities (Adhikari \& Phuyal, 2016). They also found that a total of $96 \%$ of investors and $100 \%$ of brokers believed that politics influence the share market, and there are several factors that have an impact on the behavior of the stock market, such as the decisions of brokers and investors (Adhikari \& Phuyal, 2016).

Allita and Zaiane (2017) tested the relationship between stock market volatility and political, social, and economic events. They used data from the financial companies' index, exchange rate, and tuna index, the composite index from the Tunisian market, in the period from 2010 to 2015, using the EGARCH model. They concluded that political and social events increase the volatility of financial companies, but the exchange rate is affected by economic and social events (Allita \& Zaiane, 2017).

\subsection{Events and Trading Volume}

Omran and McKenzie (2000) used the GARCH model to test the interference between trading volume and conditional variance of trade. They obtained data from the United Kingdom stock exchange market and concluded the following:

- Variability in trading volume cannot be interpreted by publicly available information but also by noninformation trade as a result of events.

- The stock market return moved too much due to variability in trading volume, fundamentals, and changes in effective risk aversion of market participants (Omran \& McKenzie, 2000).

Mustafa (2002) concluded that when events arise like in Pakistan on May 28, 1998, it changes the correlation between the trading volume and stock return in the KSE 100 index, and the trading volume decreased from 16 million to 9 million due, which also caused the stock return to decrease. The occurrence of new events changes the trading volume and subsequently changes the stock price and returns (Mustafa, 2002).

Malik and Ahmed (2009) tested the effect of market risk on daily trading activity and stock returns in the Karachi exchange market in the period from 2008 to 2009. They used the Phillips-Perron unit root test, correlation, and regression, concluding that:

- There is a positive correlation between trading activity and stock return. 
- An instability event has a significant effect on prices, and trading activity has explanatory power in addition to the present returns and volatility.

- The stock market moved too much due to changes in effective risk aversion.

- There is a negative impact of events on stock return and trading volume (Malik \& Ahmed, 2009).

Akysha (2009) executed close studies to explain the impact of different events on aggregate stock market trading volume and daily stock return during 2007 to 2008 in the Pakistan stock exchange based on event study. He used person correlation, regression, and t-value to examine the instability in the stock market as result of the events and the volatility in stock returns due to the changes in trading volume. He reached the following conclusions: (a) the events had a significant effect on trading volume and stock return in the KSE100 index; (b) the stock market moved too much due to variability in trading volume, aggregate expected returns, and changes in effective risk aversion of market participants; and (c) the relation between the trading volume and stock market return vibrate depending on the nature of the event (Akysha, 2009).

\section{Data and Methodology}

To answer the main question and subquestions, the event study methodology was used as follows.

\subsection{Data of the Study}

The data used in this study are considered by virtue of the scientific classification secondary data, both in those related to the previous studies and the quantitative data that were relied upon in the test of study hypotheses. This concerns two types of data, namely closing prices and the number of trading transactions.

\subsection{Research Community and Study Sample}

The research community includes all companies listed on the Egyptian Stock Exchange. According to the official website of the Egyptian Stock Exchange, there are about 213 listed companies. The sample of this study includes 30 EGX30 companies listed on the exchange. The data for these companies are analyzed for the period from December 2010 to December 2012, which is the period for which data are available.

The event study methodology used assumes that the date of the event is $t=0$ and determines the period after the event to test the size and speed of the market reaction to the event. We also determined the period immediately prior to the event to test the leakage of event information before announcing it to all investors and the period that includes the day of the event and the preceding period.

\section{Model of the Study}

Through the conceptual model, a study hypotheses can be formulated, where the January events can be considered the independent variable and the fluctuation of returns, trading volume, and closing price are the dependent variables. This model shows that:

- The January events can be divided into two groups:

- The first group includes the period before the January events as a dummy variable $=0$.

- The second group includes the period after the January events as a dummy variable $=1$.

- Price fluctuation: The average stock return achieved pre- and post-January events can be measured as follows: Pt- 1 - P/Pt-1.

- Trading volume: This paper utilized the variability of trading volume before and after the event to find the average of the trading volume. To measure trading activity, we use the logarithm of the percentage change in the volume of trading in each session of the event period through the following equation: $\log \mathrm{TA} \mathrm{j}, \mathrm{t} / \mathrm{TAj}, \mathrm{t}-1 \times 100$.

- The closing price: The researcher tries to measure closing prices before and after the event.

Therefore, the measurable hypotheses can be formulated as follows:

$\mathrm{H} 1$ : There is no significant association between the January events and return fluctuation.

Fluc $=\alpha+\beta 0$ Rev pre $+\beta 1$ Rev post + Error

$\mathrm{H} 2$ : There is no significant association between the January events and trading volume.

$T V=\alpha+\beta 0$ Rev pre $+\beta 1$ Rev post + Error

$\mathrm{H} 3$ : There is no significant association between the January events and closing price.

Closing $=\alpha+\beta 0$ Rev pre $+\beta 1$ Rev post + Error 


\section{Results}

\subsection{Descriptive Analysis}

Descriptive statistics are used to describe the basic features of the data in a study. They provide simple summaries about the sample and the measures, and they form the basis of virtually every quantitative analysis of data.

Table 1. Descriptive analysis before January events

\begin{tabular}{llll}
\hline \multicolumn{1}{c}{ Variables } & \multicolumn{1}{c}{ Return } & \multicolumn{1}{c}{ Ln Trading volume } & Closing \\
\hline Mean & 0.10457 & 4.605324 & 10.47781 \\
Maximum & 4.659375 & 16.22844 & 92.44000 \\
Minimum & -0.81911 & -6.6998 & 0.560000 \\
Std. Dev. & 0.696481 & 1.14836 & 16.12914 \\
Skewness & 4.528488 & -0.0591 & 3.6551 \\
Kurtosis & 23.878 & 13.493 & 16.8934 \\
Jarque-Bera & 129417.3 & 27525.8 & 61616.34 \\
Probability & 0.0000 & 0.0000 & 0.0000 \\
Observations & 6000 & 6000 & 6000 \\
\hline
\end{tabular}

Table 1 illustrates that the average of return $=10 \%$, in trading volume $=4.6$, and closing price $=10.5$, and the standard deviation of return $=0.7$, in trading volume $=1.15$, and closing price $=16$. In addition, the data do not follow normal distribution, according to the Jarque-Bera test.

Table 2. Descriptive Analysis after January Events

\begin{tabular}{llll}
\hline \multicolumn{1}{c}{ Variables } & \multicolumn{1}{c}{ Return } & LnTrading volume & \multicolumn{1}{c}{ Closing } \\
\hline Mean & 0.027455 & 4.605024 & 6.837305 \\
Maximum & 5.158140 & 13.65964 & 89.37000 \\
Minimum & -0.927273 & -5.03496 & 0.160000 \\
Std. Dev. & 0.324724 & 1.334723 & 12.45494 \\
Skewness & 8.549325 & -0.16339 & 4.412537 \\
Kurtosis & 108.443 & 10.3270 & 23.63087 \\
Jarque-Bera & 5796593 & 27333.1 & 255848.5 \\
Probability & 0.0000 & 0.0000 & 0.0000 \\
Observations & 1219 & 1219 & 12195 \\
\hline
\end{tabular}

Table 2 shows that the mean of return $=0.03 \%$, ln trading volume $=4.6$, and closing price $=6.8$, and the standard deviation of return $=0.32 \%$, in trading volume $=1.33$, and closing price $=12.5$. In addition, the data do not follow normal distribution, according to the Jarque-Bera test.

\subsection{Group Unit Root Test}

The unit root test is used to study the stationary of time series to ensure that the mean and variance are invariant over time. The value of the covariance between two time periods depends only on the distance between the two time periods and not the actual time at which the covariance is computed of the return, $\ln$ trading, and closing price through the following statistical techniques: Augmented Dickey-Fuller (ADF); Philips-Perron (PP); and Im, Pesaran, and Shin W-stat (IPSW). 
Table 3. Group unit root test before January events

\begin{tabular}{|c|c|c|c|c|}
\hline Method & Statistic & Prob. ** & Cross sections & Obs \\
\hline \multicolumn{5}{|c|}{ Null: Unit root (assumes common unit root process) } \\
\hline Levin, Lin \& Chu t* & 4.17899 & 1.0000 & 3 & 17951 \\
\hline \multicolumn{5}{|c|}{ Null: Unit root (assumes individual unit root process) } \\
\hline Im, Pesaran and Shin W-stat & -22.8690 & 0.0000 & 3 & 17951 \\
\hline ADF - Fisher Chi-square & 201.708 & 0.0000 & 3 & 17951 \\
\hline PP - Fisher Chi-square & 186.947 & 0.0000 & 3 & 17990 \\
\hline
\end{tabular}

Table 4. Group unit root test after January events

\begin{tabular}{l|c|c|c|c}
\hline Method & Statistic & Prob.** & Cross sections & Obs \\
\hline Null: Unit root (assumes common unit root process) \\
Levin, Lin \& Chu t* & -0.28438 & 0.3881 & 3 & 36558 \\
Null: Unit root (assumes individual unit root process) & & \\
Im, Pesaran and Shin W-stat & -32.4391 & 0.0000 & 3 & 36558 \\
ADF - Fisher Chi-square & 174.161 & 0.0000 & 3 & 36558 \\
PP - Fisher Chi-square & 114.092 & 0.0000 & 3 & 36579 \\
** Probabilities for Fisher tests are computed using an asymptotic Chi-square \\
distribution. All other tests assume asymptotic normality.
\end{tabular}

According to Tables 3 and 4, it is revealed that stationary of the time series of the return, $\ln$ trading and closing price at level 1 (0) based on the constant level, through to the following criteria: IPSW, PP, ADF, at a significance level less than 0.05 .

\subsection{Cointegrating Equation Model}

The Phillips-Ouliaris cointegration test was used to measure the existence of long-run equilibrium relationships among nonstationary time series variables of return, trading volume, and closing price, before and after January events as follows:

Table 5. Cointegrating Model between Dependent Variables before January Events

\begin{tabular}{ccccc}
\hline Dependent & tau-statistic & Prob.* & z-statistic & Prob.* \\
\hline Closing & -4.111051 & 0.0178 & -33.56436 & 0.0135 \\
LnTrading volume & -201.1167 & 0.0000 & -6995.099 & 1.0000 \\
Return & -125.2673 & 0.0000 & -23204.50 & 1.0000 \\
\hline
\end{tabular}

Table 6. Cointegrating Model between dependent variable before January events

\begin{tabular}{ccccc}
\hline Dependent & tau-statistic & Prob.* & z-statistic & Prob.* \\
\hline Closing & -6.704076 & 0.0000 & -89.57442 & 0.0000 \\
LnTrading volume & -272.7573 & 0.0000 & -14251.60 & 1.0000 \\
Return & -186.2045 & 0.0000 & -50413.67 & 1.0000 \\
\hline
\end{tabular}

According to Tables 5 and 6 , it is revealed that there is long-term equilibrium relationships among the dependent variables (return, trading volume, and closing price) based on the Tau-statistic, at a significance level less than 0.05. 


\subsection{Testing the Research Hypotheses}

In econometrics, the ARCH model is a statistical model for a time series. The GARCH and ARCH models are used to study the relationship between the independent variable (January events) and the dependent variables (return fluctuation, trading volume, and closing price), and the percentage of variance in errors and the ratio of the interpretation of the independent variables and dependent variables, which can be accessed by using the interpretation coefficient $\mathrm{R} 2$ by examining the extent of variance.

5.4.1 Testing the Validity of H1:

Table 7. The Relationship Between January Events and Return Fluctuation

\begin{tabular}{lrrrl}
\hline \multicolumn{1}{c}{ Variable } & Coefficient & Std. Error & z-Statistic & Prob. \\
\hline REV & 0.026261 & $2.21 \mathrm{E}-05$ & 1189.302 & 0.0000 \\
$\mathrm{R}(-1)$ & -0.415282 & 0.005118 & -81.14427 & 0.0000 \\
$\mathrm{C}$ & 0.013187 & $2.87 \mathrm{E}-05$ & 459.1452 & 0.0000 \\
& Variance Equation & & \\
& 0.081235 & 0.000393 & 206.4797 & 0.0000 \\
RESID(-1)^2 & 0.271062 & 0.007277 & 37.25100 & 0.0000 \\
GARCH(-1) & 0.647703 & 0.007172 & 90.31179 & 0.0000 \\
GARCH(-2) & & 0.196340 & \\
R-squared & & 0.196252 & \\
Adjusted R-squared & & 1.277022 & \\
Durbin-Watson stat & & 0.079562 & \\
F-statistic & & 0.7779 & \\
Prob. F(1,18191) & & 0.079570 & \\
Obs*R2 & & 0.7779 & \\
Prob. Chi-Square(1) & & & \\
\hline
\end{tabular}

The results of Table 7 illustrate that:

- Through R2, we find that independent variables are interpreted at $19.6 \%$ of the total change in the dependent variable (return fluctuation). The rest of the R2 ratio (i.e. 80.4\%) arise from two main elements; the random error of the equation and the absence of other explanatory variables that were supposed to be included in the equation.

- $\quad$ The $\mathrm{Z}$ test was used to test the significance of the model as a whole. The value of the $\mathrm{Z}$ test (i.e. 0.00) indicates a highly positive significant association between the January events and return fluctuation. Therefore, price fluctuation increased before, during, and after the events of January. Accordingly, the null hypothesis will be rejected, and we accept the alternative hypothesis. Thus, the model results show that there is a significant association between the January events and return fluctuation.

- The ARCH-LM value represents about 0.079 ; thus, it is greater than 0.05 , which is not significant. 


\subsubsection{Testing the Validity of $\mathrm{H} 2$ :}

Table 8 The Relationship Between January Events and Trading Volume

\begin{tabular}{lcccc}
\hline \multicolumn{1}{c}{ Variable } & Coefficient & Std. Error & z-Statistic & Prob. \\
\hline REV & -0.003487 & 0.009611 & -0.362771 & 0.7168 \\
LNTRADIN(-1) & -0.546679 & 0.007061 & -77.42012 & 0.0000 \\
LNTRADIN(-2) & -0.206606 & 0.007371 & -28.02887 & 0.0000 \\
C & 8.063254 & 0.056901 & 141.7064 & 0.0000 \\
& Variance Equation & & \\
C & 0.009611 & 0.000522 & 18.41015 & 0.0000 \\
RESID(-1)^2 & 0.051998 & 0.002919 & 17.81378 & 0.0000 \\
RESID(-1)^2*(RESID(-1)<0 & 0.029432 & 0.009724 & 3.026818 & 0.0025 \\
RESID(-2)^2*(RESID(-2)<0 & 0.022559 & 0.009962 & 2.264525 & 0.0235 \\
GARCH(-1) & 0.913761 & 0.002713 & 336.7626 & 0.0000 \\
R-squared & & 0.262044 & & \\
Adjusted R-squared & & 0.261922 & & \\
Durbin-Watson stat & & 2.154712 & & \\
F-statistic & & 1.235729 & & \\
Prob. F(8,18184) & & 0.2732 & & \\
Obs*R2 & & 9.885351 & & \\
Prob. Chi-Square(8) & & 0.2732 & \\
Scaled explained SS & & 17.22936 & \\
Prob. Chi-Square(8) & & 0.0278 & \\
\hline
\end{tabular}

- According to R2, the January events demonstrate $26 \%$ of the total variance in trading volume, and the rest of the R2 ratio (i.e. $74 \%$ ) arise from two main elements; the random error of the equation and the absence of other explanatory variables that were supposed to be included in the equation.

the other ratio is due to random error in the equation or perhaps not to include other independent variables that were supposed to be included in the model.

- The $\mathrm{Z}$ test represents about 0.71 ; therefore, there is no significant impact between the January events and trading volume at the significance level of 5\%, but the trading activity decreased before, during, and after the events of January. Accordingly, the null hypothesis will be rejected, and we accept the alternative hypothesis. Thus, the model results show that is a significant relationship between the January events and trading volume. 


\subsubsection{Testing the Validity of $\mathrm{H} 3$ :}

Table 9. The Relationship Between January Events and Closing Price

\begin{tabular}{lrrrr}
\hline \multicolumn{1}{c}{ Variable } & Coefficient & Std. Error & z-Statistic & Prob. \\
\hline REV & -0.100184 & 0.001752 & -57.19049 & 0.0000 \\
LOG(CLOSING(-1)) & 0.911728 & 0.000905 & 1007.797 & 0.0000 \\
C & 0.181732 & 0.002113 & 85.99098 & 0.0000 \\
& Variance Equation & & \\
RESID(-1)^2 & 0.006458 & $9.41 \mathrm{E}-05$ & 68.62704 & 0.0000 \\
GARCH(-1) & 0.993542 & $9.41 \mathrm{E}-05$ & 10557.68 & 0.0000 \\
R-squared & & 0.923032 & \\
Adjusted R-squared & & 0.923023 & \\
Durbin-Watson stat & & 3.354852 & \\
F-statistic & & 0.913880 & \\
Prob. F(4,18189) & & 0.4547 & \\
Obs*R2 & & 3.655790 & \\
Prob. Chi-Square(4) & & 0.4546 & \\
Scaled explained SS & & 78584.22 & \\
Prob. Chi-Square(4) & & 0.0000 & \\
\hline
\end{tabular}

- $\quad \mathrm{R} 2$ refers to the independent variable (January events), representing $92.3 \%$ of the total change in the dependent variable (closing price). The rest of the R2 ratio (i.e. 7.7\%) arise from two main elements; the random error of the equation and the absence of other explanatory variables that were supposed to be included in the equation.

- According to the $\mathrm{Z}$ test, we conclude that there is a negative significant association between the January events and closing price since the significance level is less than 0.05 . Therefore, we reject the null hypothesis, and accept the alternative hypothesis. Hence, the results reflect a significant association between the January events and closing price.

- $\quad$ ARCH-LM equals 0.91388; thus, it is greater than 0.05, which is not significant.

\section{Conclusion}

The literature review shows conflicting views among researchers on the effect of January events on the stock performance. To test this phenomenon in the Egyptian Stock Exchange, we divided the traded shares into two main categories: stocks before January events and stocks after January events. By examining the return fluctuation, trading volume, and closing price, the results show that:

- January events may help in increasing stock return fluctuation.

- January events may contribute to decreasing trading volume.

- January events may contribute to decreasing closing price.

Our findings show that the January events in Egypt had three important results. First, the return fluctuation increased significantly pre- and post-January events because the stock market moved too much due to changes in the fundamentals, total expected returns, and changes in ineffective risk aversion of market participants due to the nature of the event. This result is in confirmation with those of Omran (2015), Murtaza et al. (2015), and Allita and Zaiane (2017). Second, there was a significant decrease in trading volume pre- and post-January events because the occurrence of new events changed the trading volume, which subsequently changed the stock price and returns. This result was also accepted by Omran and McKenzie (2000), Mustafa (2002), and Malik and Ahmed (2009). Third, there was a significant decrease in closing price pre- and post-January events because there were enormous declines in equity prices that persisted since the beginning of the revolution. The Egyptian stock exchange was closed for 2 months. This result was also accepted by Omran (2015), Abdelbaki (2013), Murtaza et al. (2015), and Mnif and Kammoun (2015). 


\section{References}

Abdelbaki, H. H. (2013a). The Arab Spring: Do we need a new theory? Journal of Modern Economy, 4, 187-196. http://dx.doi.org/10.4236/me.2013.43020

Abdelbaki, H. H. (2013b). The impact of Arab Spring on stock market performance. British Journal of Economics, Management \& Trade, 3(3), 169-185. https://doi.org/10.9734/BJEMT/2013/3768

Adhikari, N., \& Phuyal, R. K. (2016). Influence of political events on stock market volatility in Nepal. International Journal of Economic Research, 13(7), 2765-2778.

Akysha, M. S. (2009). Trading volume and stock return: The impact of events in Pakistan on KSE 100 indexes. International Review of Business Research Papers, 5(5), 373-383.

Allita, A. B., \& Zaiane, S. (2017). The impact of news events on the Tunisian stock market volatility: A post-revolutionary study. Corporate Ownership \& Control, 14(2), 230-237. https://doi.org/ $10.22495 /$ cocv14i2c1p9

Beaulieu, M. C., Jean, C. C., Essaddam, N. (2005). The impact of political risk on the volatility of stock returns: The case of Canada. Journal of International Business Studies, 36, 701-718. https://doi.org/10.1057/palgrave.jibs. 8400160

Chau, F. Deesomsak, R., \& Wang, J. (2014). Political uncertainty and stock market volatility in the Middle East and North African (MENA) countries. Journal of International Financial Markets, Institutions \& Money, 28, 1-19. https://doi.org/10.1016/j.intfin.2013.10.008

Khan, M. T., Saif, N., Rehman, S. U., Roohullah. (2013). Stock market reaction to political events evidence from Pakistan. Journal of Economics and Sustainable Development, 4(1), 165-174.

Malik, H., \& Ahmed, S. (2009). Impact of political event on trading volume and stock return: The case of KSE. International Review of Business Research Papers, 5(4), 354-364. https://doi.org/10.1108/JEAS-03-2013-0011

Mnif, A. T., \& Kammoun, A. (2015). Arab spring and stock market crises: Evidence from the countries in the MENA region. Global Advanced Research Journal of Management and Business Studies, 4(7), 267-278.

Murtaza, H., ulhaq, M. A., Ali, R. (2015). Impact of major political events on stock market returns of Pakistan. Public Policy and Administration Research, 5(4), 69-83.

Mustafa, K. (2002). The performance of Karachi stock exchange since 1990s: A review. Journal of Social Sciences \& Humanities, 49(2), 12-26.

Omran, M. F. (2015). Risk assessment of the Egyptian stock market in the wake of the Arab Spring, Journal of Economic and Administrative Sciences, 31(2), 66-70. https://doi.org/10.1108/JEAS-05-2014-0010

Omran, M. F., \& McKenzie, E. (2000). Heteroscedasticity in stock returns data revisited: Volume versus GARCH effects. Applied Financial Economics, 10(5), 553-560. https://doi.org/10.1080/096031000416433 